\title{
TESTICULAR SUBSTANCE IMPLANTATION
}

\author{
DR. L. L. STANLEY, \\ Resident Physician, California State Prison, \\ SAN QUENTIN, CALIFORNIA
}

Brown-Séquard (1) in 1889 made a number of experiments with an extract produced from the testicles of various animals. $\mathrm{He}$ became so convinced of the beneficial effects of this material when injected into older animals, that he determined to experiment with it upon himself.

On May 15, with the assistance of his co-workers, he excised one of the testicles from a vigorous dog two years of age, cut it into pieces, ground it in a mortar with a small amount of water, and expressed the fluid. By filtration about $41 / 2$ c.c. of extract was obtained. He injected 1 c.c. of this extract subcutaneously into his own leg, repeating the injection about every five to ten days, until he had received ten treatments in all.

The last five were made from the extract of guinea pig testicles, which was injected under the skin of the abdomen and arm.

At this time Brown-Sécuard was 72 years old, and so feeble that it was necessary for him to sit down after only half an hour's work in his laboratory. Although seated, he became very much fatigued after a few hours, and it was necessary to return home in a carriage, and immediately go to bed after a sparse and hurried supper. For the preceding ten yeurs his weakness had been so great that he was unable to sleep, and arose excessively tired.

The day after the first injection, and still more after the others, he claimed that a radical change took place in him, and by the first of June he had regained all the force which he possessed a number of years before. A considerable amount of work in the laboratory scarcely tired him, and, to the astonishment of his principal assistants, he was able to experiment for many hours, and in walking about had no need for help. On May 23rd, after three and one-quarter hours of very fatiguing experimental work, he was so slightly tired that after dinner he was 
able to begin work on the report of some very difficult problems. It had been twenty years since he had done any work after supper.

Because of a natural impetuosity, Brown-Séquard had the habit, up until he became sixty years old, of running up and down stairs. This gradually lessened, and it became necessary for him to hold to the balustrade, but after the second injection he regained his lost propensities, and without realizing it regained his old habit.

His limbs showed a very noticeable increase in strength. The flexors of his right arm registered 34 kilograms before, but after the treatments increased to 41 . Particular attention had been paid for many years by him to the registering of this strength by the dynamometer.

He observed the force of the jet of urine, and affirmed that the greatest length of the stream during the six days preceding the first injection was at least a quarter less than that which followed during the next twenty days.

He commented, moreover, that perhaps the most distressing misfortune of old age consists in the inability to defecate. With him the expulsion of fecal material had become most laborious during the preceding twelve years, and had become almost impossible without the aid of purgatives and artificial means. During the two weeks which followed the first injection, a radical change took place in the reflex of defecation. He had less use for laxatives, and the expulsion of feces equally as large and hard was accomplished without mechanical assistance or lavage. There had been a return to normal state of many years before.

He added that intellectual effort had become easier than for many years, and that many other forces not lost, but decreased, had been notably increased.

Subsequent to his experiments upon himself, Brown-Séquard reported other cases which were benefited. He believed that the testicular extract had an influence particularly on the spinal cord.

Brainard made injections in over two hundred people, using extracts from the testicles of healthy young rams. He tied the spermatic veins and vasa of the ram as far away from the testicle as possible, and then expressed the fluid. Mixing this with distilled water, and filtering, he injected from 15 to 60 minims 
in the deltoid muscle. After the first injection in many cases of weakness without definite disease, he noticed a beneficial effect. In three cases of locomotor ataxia, Brainard states, more favorable and pronounced effects resulted than in any others. Five cases of muscular rheumatism and four of sciatica were relieved or entirely cured of pain. Some of the cases of Brainard reported as not improved, were thought by Brown-Séquard to have received insufficient injections.

In cases of tuberculosis, Brown-Séquard noticed beneficial effects, as increase in appetite, strength, and a fall in temperature. He gave daily injections of 1 c.c of testicular material. $\mathrm{He}$ also reports cases of other diseases in which conditions of mental depression, hemiplegia, and myopathies were greatly relieved.

In the latter part of 1918 , the first experiments of engrafting human testicles from recently executed prisoners to senile recipients were begun at San Quentin Penitentiary, and to date twenty-one such cases have been treated.

In 1920, animal glands were substituted for the human, and were not grafted to the recipients testes, but were merely laid in the pampiniform plexus of the scrotum. Many of these sloughed out, for too large a piece was used. After a time, varying from three days to as many weeks, the site of operation would open up and discharge a quantity of yellowish necrotic material, usually devoid of bacteria.

Later smaller pieces were used. A cross section of a ram's testicle about the size of a dollar was cut and placed in the scrotum. Many of these remained without sloughing, and very gradually were absorbed.

As the scrotum is subject to considerable trauma, and is difficult to keep clean, it was determined to imbed the section of ram's testicle on the fascia, overlying the rectus muscle of the abdomen. With the skin injected with $1 / 2$ per cent novocain, an incision was made down to the rectus; closed curved Mayo's scissors were then run along on top of the fascia at right angles to the incision, opened and withdrawn, leaving a tunnel between the fascia and fat. This was held open with retractors, and the section of testicle carefully inserted. The incision was closed with two silkworm gut sutures. With this procedure there were 
very few sloughs, but it was necessary for the patient to "go easy" for a week, until the wound had healed.

A number of these implants were removed after a variable time, and it was found that they were not alive, but were necrotic, and were being gradually absorbed.

Believing that all the testicular substance would undergo the same process, however placed in the system, it was determined to inject it by syringe without undue maceration.

The syringe employed is one devised by Joseph Beck, for paraffin. It holds about 4 grams. The barrel of the syringe is filled with strips of the fresh testicle. The piston is attached and the substance slowly injected through a large needle, the skin being first infiltrated with a few drops of novocain. About one gram of the testicle is injected in each of four places, radially from the single point of entrance.

With this method the danger of slough is reduced to a minimum. The patient does not have to "go easy" for a week, but may continue with his work.

There is usually no inconvenience, although there may be some redness for the first few days about the site of injection on the abdomen, and later on a sense of itching. The injected substance may be felt under the skin for weeks and months, until it is all absorbed.

The material used is best taken from a ram, goat, or boar which has reached maturity, preferably a year to eighteen months old. As soon as the animal is killed, the whole scrotum is resected between clamps and brought to the hospital. Here the external hair is clipped off, the skin painted with iodine, and with absolutely aseptic technic the skin incised. The edges are grasped with hemostats and held back. The next layer is likewise grasped and retracted. There are many coverings before the tunica is reached, and each may be carefully and aseptically opened.

The tunica vaginalis is then opened and the testicle caught with a large hemostat and removed to a sterile towel or basin. Here it is opened, and the strips cut for filling the syringe.

The abdomen or site of injection of the patient is cleaned with alcohol. After the operation the needle hole in the skin is covered with Tincture Benzoin Compound, and a little cotton. This may be in turn covered with a small strip of adhesive tape. 
Because it is not always possible to obtain testicular material just when it is wanted, a plan for preserving was devised. As soon as the testicle is removed aseptically, it is immersed in pure vaseline, warmed to liquid state. This keeps out all air. Then the container is placed in the refrigerating vats of the ice plant and kept frozen at $-12^{\circ} \mathrm{F}$.

When ready for use the testicle has the consistency of an ice cream brick. Glands preserved in this way have been used as long as thirty days after death of the animal. Refrigeration does not seem to affect the potency.

Up to the present time over three hundred cases have been treated with animal testicular material. These were not selected but were taken in order of their application. After the first twenty or thirty prisoners had received the glands and reported among their fellow prisoners the good results they had obtained, many applications were received.

As there is very little pain, and no inconvenience to the process, many were willing to test it.

Among those treated were cases of neurasthenia, senility, asthma, paralysis agitans, epilepsy, dementia precox, diabetes, locomotor ataxia, impotency, tuberculosis, paranoia, gangrene of toe, atrophied testicles, rheumatism, and, in fact, many otherillnesses of chronic character not amenable to treatment.

Finding that the injection of animal testicular substance caused no ill effects, and at most only a slough, it was thought worth while to try it on any case which presented.

From these experiments it may be said that animal testicular substance injected into the human body does exert decided effects.

Some of those receiving this treatment claim that their eyesight is improved, the appetite is increased, that there is a feeling of buoyancy, a joy of living, an increased energy, loss of tired feeling, increased mental activity and many other beneficial effects. These results are not easy to demonstrate, and one must rely to a considerable extent on the patient's statements.

However, when the psychology of a prisoner is considered, one may be assured that if no beneficial effects were derived, the news would rapidly spread among the inmates and it would be impossible to induce others to take the treatment. As a 
matter of fact, applications come in every day from the convicts for the "glands" and the demand is very great. Some even want a second and third injection, feeling that if one does good, more will do better.

In the series, eight cases of asthma have been treated. All have been helped, and four claim that they have had no reeurrences.

If it be true that there is an inter-relation between the various glands of internal secretion, the theory might be advanced that the injection of testicular substance so acts upon the adrenal glands, that an increase of adrenin is thrown into the system, thereby influencing the asthmatic attacks.

In four cases of acne, young men from 18 to 25 years of age have received injections. The eruptions have been markedly decreased. As acne is usually a disease of early manhood, may it not be possible that the maturing interstitial tissue has less influence on the sebaceous glands than that which the patient acquires as he grows older? Acne generally disappears when the patient enters manhood.

In tuberculosis in the various stages and conditions, eleven patients were treated. Most of them showed a temporary gain in weight, appetite, sexual manifestations, and general well-being. Three advanced cases, however, died. The injections were made only as a last resort, with little hope of their being of any value.

This procedure has been carried out in about sixteen mental cases, ranging from neurasthenia to manic-depressive insanity. Most of the subjects showed some change. One case of paranoia has apparently lost his delusions of persecution, improved physically, and works very well.

Almost all the subjects report increased sexual activity. Many who have not had erections for years claim that their virility has been restored.

One melancholiac, who would not talk or show any activity whatever, was observed to have an erection a few days after an implantation. He died several months later from inanition due to refusal to take food.

Experimentation is now under way with six white rats in separate revolving cages, to compare the amount of work done before and after implantation of testicular substance. 
Further work will also be done on prisoners, testing the effects of single and multiple injections.

These observations were undertaken with an unbiased mind, and with the endeavor to pursue the truth, wherever it may lead.

\section{BIBLIOGRAPHY}

Brown-Séquard: Expérience démontrant la puissance dynamogénique chez l'homme d'un liquide extrait de testicules d'animaux. Arch. de physiol. (Paris), 1889, 5 s., 1, 651.

: Nouveaux faits relatifs à l'injection souscutanée chez l'homme d'un liquide extrait de testicules mammiferes. Arch. de physiol (Paris), 1890, 5 s., 2, 204.

: Du rôle physiologique et therapeutique d'un suc extrait de testicules d'animaux d'après nombre de faits observés chez l'homme. Arch .de physiol. (Paris), 1889, 5 s., 1, 738. 